\title{
Etiologies, diagnostic work-up and outcomes of acute respiratory distress syndrome with no common risk factor: a prospective multicenter study
}

\author{
Nicolas de Prost ${ }^{1,2,13^{*}+}$ D , Tài Pham ${ }^{3,4,5,6 \dagger}$, Guillaume Carteaux ${ }^{1,2}$, Armand Mekontso Dessap ${ }^{1,2}$, \\ Christian Brun-Buisson 1,2, Eddy Fan7, Giacomo Bellani ${ }^{8,9}$, John Laffey ${ }^{10,11}$, Alain Mercat ${ }^{12}$, Laurent Brochard ${ }^{6}$, \\ Bernard Maître ${ }^{1,2}$, for the LUNG SAFE investigators the ESICM trials group and the REVA network
}

\begin{abstract}
Background: Patients meeting the Berlin definition for the acute respiratory distress syndrome (ARDS) might lack exposure to one or more "common" risk factors and exhibit different clinical phenotype and outcomes. We aimed to compare the clinical presentation and outcome of ARDS patients with or without risk factors, the impact on hospital mortality, and to assess the diagnostic work-up performed. The current study is an ancillary analysis of an international, multicenter, prospective cohort study (the Large Observational Study to Understand the Global Impact of Severe Acute Respiratory Failure, LUNG SAFE). Patients meeting ARDS criteria within 2 days of acute hypoxemic respiratory failure onset were included in the study and categorized as having risk factors or not. Outcomes were compared using propensity score matching.

Results: Among 2813 patients, 234 (8.3\% [7.3-9.3]) had no ARDS risk factor identified. These were older, had more frequent chronic diseases and presented with less severe SOFA and non-pulmonary SOFA scores $(p<0.001)$. Compared to other ARDS, CT scan (32.1 vs 23.9\%, $p<0.001$ ) and open lung biopsy ( 2.6 vs $0.2 \%, p<0.001)$ were slightly more frequent but left heart filling pressures assessment was not (69.4 vs 68.4\%, $p>0.99)$. Among ARDS with no risk factor, 45 patients (19.2\%) had a specific diagnosis made. As compared to others, patients having ARDS with no risk factor had a lower ICU but not hospital mortality (34.6 vs 40.0\%; $p=0.12$ ). A matched cohort analysis confirmed the lack of significant difference in mortality.

Conclusion: Eight percent of ARDS patients have no identified risk factor, $80 \%$ of whom have no etiological diagnosis made. The outcome of ARDS with no risk factor was comparable to other ARDS but few had a comprehensive diagnostic work-up, potentially leading to missed curable diseases.

Trial registration clinicaltrials.gov Identifier: NCT02010073
\end{abstract}

Keywords: Respiratory distress syndrome, adult, Berlin definition, Outcomes, Diagnostic techniques and procedures

\section{Background}

The Berlin definition of the acute respiratory distress syndrome (ARDS) [1] was established to improve the

\footnotetext{
*Correspondence: nicolas.de-prost@aphp.fr

${ }^{\dagger}$ Nicolas de Prost and Tài Pham contributed equally to this work

${ }^{13}$ Service de Réanimation Médicale, Hôpital Henri Mondor, 51, Avenue du Maréchal de Lattre de Tassigny, 94010 Créteil Cedex, France

Full list of author information is available at the end of the article
}

reliability and the validity of ARDS diagnosis and to better classify patients according to the disease severity. This definition states that respiratory symptoms are to occur (or worsen) within seven days of exposure to one or more proposed "common" ARDS risk factor (e.g., pneumonia, gastric aspiration, extra-pulmonary sepsis, polytrauma). Because ARDS is a heterogeneous entity, previous studies have striven to individualize subgroups of patients 
based on the risk factors involved [2], the presence of diffuse alveolar damage or not on lung histological analysis $[3,4]$, the presence of direct or indirect lung injury [5] or, more recently, by defining subphenotypes using latent class analysis [6]. In this line, we have recently reported that $7.5 \%$ of ARDS patients had no common risk factors of the Berlin definition identified during ICU stay and that these patients showed different clinical features and outcomes than others [7], suggesting individualizing this subgroup of patients could be of interest. Of note, in this retrospective series, ARDS patients with no common risk factor identified had a comprehensive diagnostic work-up performed, including (but not limited to) chest CT scan and bronchoscopy with broncho-alveolar lavage (BAL) fluid examination in most cases, allowing for an etiological diagnosis to be obtained in $75 \%$ of cases, the main etiologies identified being immunologic, druginduced, or neoplastic disorders.

To the best of our knowledge, no large-scale prospective study has assessed the clinical phenotype, the prevalence, the management and the outcomes of ARDS patients with no common risk factor of the Berlin definition. We therefore took advantage of the Large Observational Study to Understand the Global Impact of Severe Acute Respiratory Failure (LUNG SAFE) [8] and designed the ancillary ASTEROID study (ArdS with no Risk factor from the Berlin Definition), which was approved by the steering committee of the LUNG SAFE study before patient enrollment began. We aimed to (1) determine the prevalence of ARDS with no risk factor identified; (2) evaluate the diagnostic work-up performed and the etiologies of ARDS in this subgroup of patients; and (3) compare the clinical presentation and outcome of patients having ARDS with no risk factors to those of others.

\section{Methods}

\section{Study design}

The LUNG SAFE study was an international, multicenter, prospective cohort study [8]. As previously described [8], patients were enrolled during four consecutive winter weeks (February-March 2014 in the Northern hemisphere and June-August 2014 in the Southern hemisphere) within each participating intensive care unit (ICU, $n=459$ ). Ethics committee approval was obtained by all participating ICUs and patient consent or ethics committee waiver of consent were required. ICUs were recruited by public announcements by the European Society of Intensive Care Medicine (ESICM), by national societies and networks endorsing the study, and by designated national coordinators (see Additional file 1 : e-Appendix 1) [8]. The ASTEROID study is an ancillary study, which had been designed and approved by the steering committee of the LUNG SAFE study before the enrollment period began.

\section{Patients and data collection}

All patients admitted to a participating ICU within the 4-week enrollment window and receiving invasive or non-invasive ventilation were included. Exclusion criteria were age $<16$ years or inability to obtain informed consent, when required. Following enrollment, patients were evaluated daily for acute hypoxemic respiratory failure, defined as the concurrent presence of (1) ratio of arterial oxygen tension to inspired fraction of oxygen $\left(\mathrm{PaO}_{2} /\right.$ $\mathrm{F}_{\mathrm{I}} \mathrm{O}_{2}$ ) of $300 \mathrm{mmHg}$ or less; (2) new pulmonary parenchymal abnormalities on chest $\mathrm{x}$-ray or computed tomography; and (3) ventilatory support with continuous positive airway pressure, expiratory positive airway pressure, or positive end-expiratory pressure (PEEP) of $5 \mathrm{cmH}_{2} \mathrm{O}$ or more. Day 1 was defined as the first day that acute hypoxemic respiratory failure criteria were met. Investigators were prompted to provide an expanded data set on the electronic case report form for days 1, 2, 3, 5, 7, 10, 14, 21 , and 28 or at ICU discharge or death.

Patients meeting ARDS criteria on day 1 or 2 were included in the ASTEROID analysis and categorized as having "common" risk factors (Berlin definition [1]) or not depending on the identification of ARDS risk factors by managing physicians both upon ARDS diagnosis and during ICU stay ("late-identified risk factors"). Specific additional data were prospectively collected for patients having no risk factors (Additional file 1: e-Appendix 2). Patient outcomes included date of liberation from mechanical ventilation and vital status at ICU discharge and at either hospital discharge or at day 90 , whichever occurred earlier. The primary end-point of the study was the prevalence of ARDS with no risk factor identified. Secondary endpoints were: (1) the comparison of clinical characteristics and outcomes of ARDS patients with and with no risk factor identified and (2) the diagnostic work-up performed and the etiologies of ARDS in this subgroup of ARDS with no risk factor identified.

\section{Statistical analysis}

Continuous variables are reported as median (1st-3rd quartiles) or mean \pm standard deviation (SD), as appropriate. Parametric or nonparametric tests were used according to the distribution of variables. Differences in categorical variables were analyzed using the Chi-square or the Fisher exact test or the McNemar test for matched patients, as appropriate. Continuous variables were compared using the Student's $t$ test or the Wilcoxon ranksum test and the corresponding paired tests for matched patients, as appropriate. The relationship between the variable "no ARDS risk factor" and hospital mortality 
was assessed by the Kaplan-Meier method (patients were considered alive at day-60 if they were discharged alive before day-60) and by logistic regression. In-ICU and hospital mortality were compared between propensitymatched ARDS patients having one or more common risk factor identified or not. Covariates presumed to be associated with the presence of one or more ARDS risk factor or with hospital mortality were included in a multivariable analysis with "identification of $\geq 1$ ARDS risk factor" as the dependent variable to determine the propensity score of this variable for each patient (see Additional file 1). Propensity score methods are usually used to reduce the bias in estimating treatments effects and the likelihood of confounding when analyzing non-randomized observational data [9]. In the current study, we used a propensity score method in order to assess the impact of the lack of ARDS risk factor on patient outcomes. Patients with one or more identified risk factor were thus matched with other patients according to the propensity score, using a 1:1 matching procedure. The relative change in the hazard of the ICU and hospital mortality were then assessed by regressing survival on the identification of a risk factor by using a univariate Cox proportional hazards model accounting for the matched nature of the sample. Twotailed $p$ values of less than 0.05 were considered statistically significant. Statistical analyses were performed with R3.2.3 (http://www.R-project.org).

\section{Results}

\section{Prevalence of ARDS with no risk factor identified}

A total of 4499 patients met the acute hypoxemic respiratory failure criteria of the LUNG SAFE study, of whom 2813 (62.5\% [61.1-63.9]) had ARDS on day 1 or 2 (Fig. 1) and were included in the current analysis. In this cohort, 2547 patients (90.5\% [89.4-91.6]) had a risk factor for ARDS identified upon ARDS diagnosis, while 266 (9.5\% [8.4-10.6]) had no risk factor identified. Among these, 32 patients had a late-identified risk factor, leading to a prevalence of ARDS with no risk factor identified during ICU stay of $8.3 \%$ [7.3-9.3] $(n=234 / 2547)$.

\section{Clinical presentation of ARDS patients with and without risk factor}

As compared with other patients with ARDS, those having no risk factor identified upon ARDS diagnosis were older ( $65 \pm 15$ vs $61 \pm 17, p<0.001)$ and had

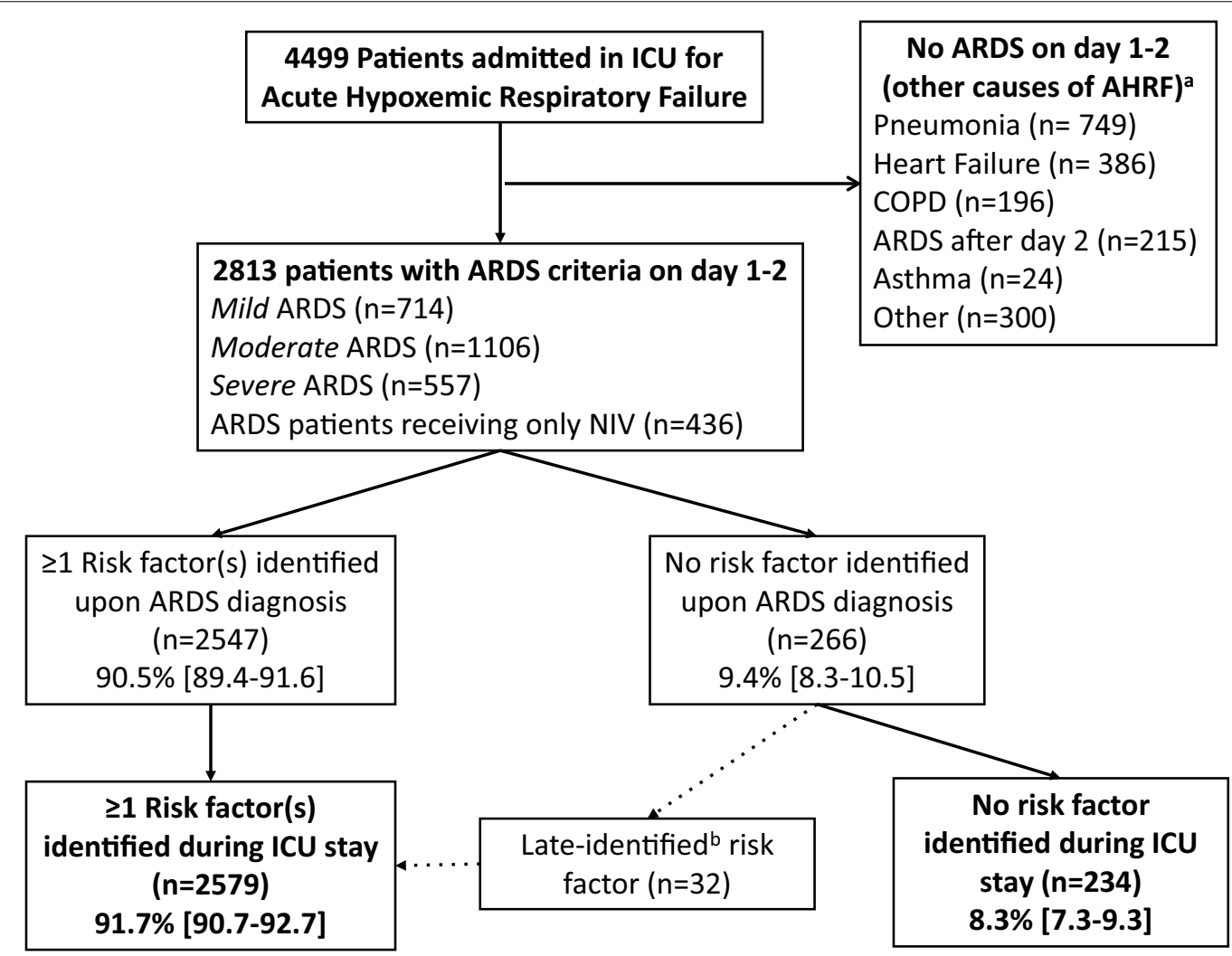

Fig. 1 Flow of patients with acute hypoxic respiratory failure (AHRF) enrolled in the study. ICU, intensive care unit; ARDS, acute respiratory distress

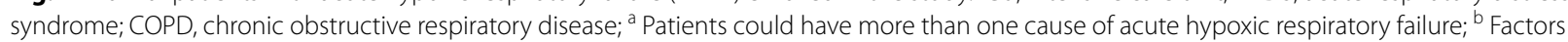
identified during the course of ICU stay 
more comorbidities, including COPD (34.2 vs 20.4\%, $p<0.001)$, diabetes (27.8 vs $21.2 \%, p=0.025)$, cardiac (16.2 vs $9.8 \%, p=0.003$ ) or renal (16.2 vs $9.6 \%, p=0.002)$ failure, but less frequent hematological malignancy (1.7 vs $5.2 \%, p=0.027$ ) (Table 1 ). In contrast, these patients presented with less severe pulmonary (ARDS severity) and non-pulmonary organ failures, as reflected by lower total $(8.5 \pm 3.7$ vs $9.5 \pm 4.1, p<0.001)$ and non-pulmonary (5.3 \pm 3.7 vs $6.3 \pm 4.1, p<0.001)$ SOFA scores. Differences in ventilator settings (PEEP, peak inspiratory pressure, $\mathrm{F}_{\mathrm{i}} \mathrm{O}_{2}$ levels) likely reflected differences in ARDS severity between the two groups (Table 1). Except for a greater number of ICU bed per nurse in patients with no risk factors as compared to others (Additional file 1: e-Table 1), the characteristics of ICUs did not significantly differ between groups. The rate of ARDS with no risk factor ranged from 0 to $33 \%$ among countries (Additional file 1: e-Table 2).

\section{Diagnostic investigations and management of ARDS patients with and without risk factor}

An objective assessment of left heart filling pressures was performed in $68.4 \%$ of patients having one or more ARDS risk factor identified, as compared to $69.4 \%$ of patients having no risk factor identified $(p>0.99)$ (Table 2), mainly using echocardiography. Still, even in the latter group, all investigators considered that acute hypoxemic respiratory failure was not fully explained by fluid overload. Among patients having no risk factor identified, a comparison of those who underwent an objective assessment of LHFP ( $n=160)$, as required by the Berlin definition, or not $(n=74)$ revealed that the latter had less frequently known previous history of cardiac and chronic renal failure and more frequent immunoincompetence (Additional file 1: e-Table 3), suggesting they were less likely to have a mere cardiogenic pulmonary edema. Regarding diagnostic investigations (Table 2), patients having no risk factor identified underwent slightly more frequent chest CT scans $(32.1 \%(n=75)$ vs $23.9 \%$ $(n=617), p<0.001)$ and open lung biopsy $(2.6 \%(n=6)$ vs $0.2 \%(n=5), p<0.001)$ than others. However, only a limited number of these patients underwent a more comprehensive diagnostic work-up, including bronchoscopy with BAL $(n=22,9.4 \%)$, immunological tests $(n=12$, $5.1 \%)$, and search for a pneumotoxic drug $(n=6,2.6 \%)$.

Among the subgroup of ARDS with no risk factor, 45 (19.2\%) patients eventually had an etiology for ARDS (Table 3), allowing for a targeted management, while 189 $(80.8 \%)$ had no etiology identified during ICU stay. There was no significant difference in the number of autopsies performed in patients without as compared to with ARDS risk factors $(9.4 \%(n=6 / 64$ decedents in ICU) vs $5.5 \%$ ( $n=50 / 902), p=0.26)$. Lung histological analyses obtained from open lung biopsy and autopsy revealed that diffuse alveolar damage (DAD), pulmonary edema, pneumonia, lung fibrosis and normal lung histology were the most common findings in both groups of patients (Table 4).

Regarding ARDS management, the observed differences between the two groups reflected differences in ARDS severity, with patients from the no risk factor group receiving less neuromuscular blocking agents (14.1 vs $20.0 \%, p=0.04$ ) and inhaled vasodilators (3.8 vs $7.9 \%$, $p=0.02)$. The rate of corticosteroids administration was not significantly different between groups (17.5 vs $18.1 \%$, $p=0.89$, Table 2).

\section{Patients with and without ARDS risk factor identified: prognostic comparison}

Among survivors, patients with no risk factor for ARDS identified exhibited significantly lower durations of invasive mechanical ventilation as well as of ICU and hospital length of stay, as compared to ARDS survivors having at least one risk factor identified (Table 5).

The ICU mortality was significantly lower in ARDS patients with no risk factor than in others (27.3 vs $35.0 \%$, $p=0.023$ ), but in-hospital mortality was not significantly different (34.6 vs $40.0 \%, p=0.12$ ) (Table 5). Comparison of outcomes between propensity-matched ARDS patients having one or more common risk factor identified or not during ICU stay showed no significant difference (Table 5; Fig. 2; Additional file 1: e-Figure 1 for assessing the quality of propensity score matching), except for a shorter duration of hospital stay in the latter group as compared to the former one. Kaplan-Meier curves did not show significant differences in the probability of hospital death overtime in patients without vs. with identified risk factors both in the whole cohort (Fig. $3 \mathrm{a}, p=0.13$ by the log-rank test) and in the propensity score-matched cohort (Fig. $3 \mathrm{~b}, p=0.73$ by the Cox proportional hazard model). By logistic regression analysis, there was also no significant relationship between the absence of ARDS risk factor and hospital mortality, both before and after propensity score matching (Table 6). Prognostic comparison of both groups was not altered by removing the variable "peak pressure" from the propensity score (Additional file 1: e-Figure 1, e-Table 4).

\section{Discussion}

The main results of the current study are as follows: (1) in a large, prospective, international, multicenter cohort, eight percent of patients with ARDS had no risk factor identified at the end of their ICU stay; (2) about $80 \%$ of these had no etiological diagnosis made, and, despite slightly more chest CT scans and lung biopsy performed than in other patients, specific investigations aimed at 
Table 1 Baseline characteristics of patients with ARDS meeting ARDS criteria within $\mathbf{4 8} \mathrm{h}$ of acute hypoxemic respiratory failure onset $(n=2813)$

\begin{tabular}{|c|c|c|c|}
\hline Parameters & $\begin{array}{l}\text { ARDS patients with } \geq 1 \text { risk } \\
\text { factor identified }(n=2579)\end{array}$ & $\begin{array}{l}\text { ARDS patients with no risk } \\
\text { factor identified }(n=234)\end{array}$ & $p$ value $^{\mathrm{a}}$ \\
\hline Age (years) & $61 \pm 17$ & $65 \pm 15$ & $<0.01$ \\
\hline \multicolumn{4}{|l|}{ Chronic disease } \\
\hline COPD & $527(20.4)$ & $80(34.2)$ & $<0.01$ \\
\hline Diabetes & $548(21.2)$ & $65(27.8)$ & 0.025 \\
\hline Immunoincompetence & $544(21.9)$ & $40(17.9)$ & 0.17 \\
\hline Chronic cardiac failure & $252(9.8)$ & $38(16.2)$ & $<0.01$ \\
\hline Chronic renal failure & $248(9.6)$ & $38(16.2)$ & $<0.01$ \\
\hline Active neoplasm & $210(8.1)$ & $22(9.4)$ & 0.58 \\
\hline Hematological malignancy & $134(5.2)$ & $4(1.7)$ & 0.03 \\
\hline Chronic liver failure & $106(4.1)$ & $6(2.6)$ & 0.33 \\
\hline Type of admission & & & $<0.001$ \\
\hline Medical & $1979(76.7)$ & $179(76.5)$ & \\
\hline Postoperative & $127(4.9)$ & $26(11.1)$ & \\
\hline Surgical & $365(14.1)$ & $28(12.0)$ & \\
\hline Trauma & $108(4.2)$ & $1(0.4)$ & \\
\hline ARDS severity & & & $<0.001$ \\
\hline Mild & $651(25.2)$ & $63(26.9)$ & \\
\hline Moderate & $1026(39.8)$ & $80(34.2)$ & \\
\hline Severe & $524(20.3)$ & $33(14.1)$ & \\
\hline ARDS receiving only NIV & $378(14.7)$ & $58(24.8)$ & \\
\hline Day 1 SOFA score ${ }^{b}$ & $9.5 \pm 4.1$ & $8.5 \pm 3.7$ & $<0.01$ \\
\hline Day 1 non-pulmonary SOFA score ${ }^{c}$ & $6.3 \pm 4.1$ & $5.3 \pm 3.7$ & $<0.01$ \\
\hline Worst SOFA score & $11.2 \pm 4.4$ & $9.8 \pm 4.1$ & $<0.01$ \\
\hline Worst non-pulmonary SOFA score & $8.1 \pm 4.2$ & $6.8 \pm 4.1$ & $<0.01$ \\
\hline $\mathrm{FiO}_{2}$ & $0.60[0.45-0.80]$ & $0.50[0.40-0.80]$ & 0.03 \\
\hline Total respiratory rate (1/min) & $21.8 \pm 8.9$ & $21.3 \pm 6.5$ & 0.42 \\
\hline Tidal volume (mL/kg PBW) & $7.7 \pm 2.0$ & $7.9 \pm 2.3$ & 0.20 \\
\hline In intubated patients & $7.6 \pm 1.9$ & $7.7 \pm 1.9$ & 0.59 \\
\hline In NIV patients & $8.3 \pm 2.7$ & $8.7 \pm 3.2$ & 0.52 \\
\hline Set PEEP $\left(\mathrm{cmH}_{2} \mathrm{O}\right)$ & $8.2 \pm 3.2$ & $7.5 \pm 2.4$ & $<0.01$ \\
\hline Peak pressure $\left(\mathrm{cmH}_{2} \mathrm{O}\right)$ & $25.6 \pm 8.8$ & $23.5 \pm 8.0$ & $<0.01$ \\
\hline Plateau pressure $\left(\mathrm{cmH}_{2} \mathrm{O}\right)^{\mathrm{d}}$ & $23.2 \pm 6.1$ & $22.8 \pm 5.4$ & 0.65 \\
\hline Respiratory system compliance $\left(\mathrm{mL} / \mathrm{cmH}_{2} \mathrm{O}\right)^{d}$ & $36.8 \pm 22.1$ & $33.5 \pm 15.2$ & 0.16 \\
\hline Driving pressure $\left(\mathrm{cmH}_{2} \mathrm{O}\right)^{\mathrm{d}}$ & $14.7 \pm 5.4$ & $11.8 \pm 6.0$ & 0.67 \\
\hline Standardized minute ventilation $(\mathrm{L} / \mathrm{min})^{\mathrm{e}}$ & $11.3 \pm 5.4$ & $11.9 \pm 6.0$ & 0.42 \\
\hline $\mathrm{PaO}_{2} / \mathrm{FiO}_{2}$ ratio $(\mathrm{mmHg})$ & $159 \pm 67$ & $169 \pm 68$ & 0.03 \\
\hline $\mathrm{SpO}_{2}(\%)$ & 96 [93-98] & 96 [94-98] & 0.18 \\
\hline $\mathrm{PaCO}_{2}(\mathrm{mmHg})$ & $45.6 \pm 15.3$ & $48.8 \pm 18.0$ & 0.01 \\
\hline $\mathrm{pH}$ & $7.33 \pm 0.12$ & $7.33 \pm 0.12$ & 0.90 \\
\hline
\end{tabular}

Categorical variables are shown as $\mathrm{n}(\%)$; Continuos variables are shown as median [1 st-3rd quartiles] or mean \pm standard deviation, as appropriate; ARDS: acute respiratory distress syndrome; $\mathrm{COPD}$, chronic obstructive pulmonary disease

NIV, non-invasive ventilation; SOFA: Sequential Organ Failure Assessment; $\mathrm{FiO}_{2}$, inspired fraction of oxygen; PBW: Predicted Body Weight; PEEP: Positive End-Expiratory Pressure; $\mathrm{SpO}_{2}$ : peripheral arterial oxygen saturation

a $p$ value represents comparisons across ARDS with or without known risk factor; Parametric or nonparametric tests were used according to the distribution of variables

${ }^{\mathrm{b}}$ For all SOFA scores, where data points were missing, this value was omitted and the denominator adjusted accordingly

c For computing the non-pulmonary SOFA score, the pulmonary component of the score was omitted and the denominator adjusted accordingly

${ }^{d}$ Plateau pressure values are limited to patients in whom this value was reported $(n=732)$, and in whom either an assist control mode was used or, where a mode permitting spontaneous ventilation was used, the set and total respiratory rates were equal. Patients receiving high frequency oscillatory ventilation (HFOV) or extracorporeal membrane oxygenation (ECMO) were also excluded

e Standardized minute ventilation $=$ minute ventilation $* \mathrm{PaCO}_{2} / 40 \mathrm{mmHg}$ 
Table 2 Management of ARDS patients meeting ARDS criteria within $48 \mathrm{~h}$ of acute hypoxemic respiratory failure onset $(n=2813)$

\begin{tabular}{|c|c|c|c|}
\hline Parameters & $\begin{array}{l}\text { ARDS patients with } \geq 1 \text { risk } \\
\text { factor identified }(n=2579)\end{array}$ & $\begin{array}{l}\text { ARDS patients with no risk } \\
\text { factor identified }(n=234)\end{array}$ & $p$ value $^{a}$ \\
\hline \multicolumn{4}{|l|}{ Diagnostic procedures } \\
\hline Assessment of LHFP & $1780(68.4)$ & $160(69.4)$ & $>0.99$ \\
\hline Echocardiography & $1636(63.4)$ & $151(64.5)$ & 0.79 \\
\hline Pulmonary artery catheter & $103(4.0)$ & $14(6.0)$ & 0.20 \\
\hline TTP & $166(6.4)$ & $10(4.3)$ & 0.24 \\
\hline Other methods & $155(6.0)$ & $12(5.1)$ & 0.69 \\
\hline Chest CT scan & $617(23.9)$ & $75(32.1)$ & $<0.01$ \\
\hline Number of chest CT scan & $0[0-0]$ & $0[0-1]$ & $<0.01$ \\
\hline Open lung biopsy & $5(0.2)$ & $6(2.6)$ & $<0.01$ \\
\hline \multicolumn{4}{|l|}{ Treatment of ARDS } \\
\hline \multicolumn{4}{|l|}{ Neuromuscular blocking agents } \\
\hline In the $1 \mathrm{st} 72 \mathrm{~h}$ of ARDS & $440(17.1)$ & $26(11.1)$ & 0.02 \\
\hline At any time during ICU stay & $517(20.0)$ & $33(14.1)$ & 0.04 \\
\hline \multicolumn{4}{|l|}{ Recruitment maneuvers } \\
\hline In the 1 st $72 \mathrm{~h}$ of ARDS & $446(17.3)$ & $30(12.8)$ & 0.10 \\
\hline At any time during ICU stay & $506(19.6)$ & $33(14.1)$ & 0.05 \\
\hline \multicolumn{4}{|l|}{ Prone positioning } \\
\hline In the 1 st $72 \mathrm{~h}$ of ARDS & $134(5.2)$ & $8(3.4)$ & 0.30 \\
\hline At any time during ICU stay & $190(7.4)$ & $11(4.7)$ & 0.17 \\
\hline \multicolumn{4}{|l|}{ ECMO } \\
\hline In the $1 \mathrm{st} 72 \mathrm{~h}$ of ARDS & $60(2.3)$ & $6(2.6)$ & $>0.99$ \\
\hline At any time during ICU stay & $70(2.7)$ & $8(3.4)$ & 0.67 \\
\hline \multicolumn{4}{|l|}{ Inhaled vasodilators } \\
\hline In the $1 \mathrm{st} 72 \mathrm{~h}$ of ARDS & $156(6.0)$ & $7(3.0)$ & 0.08 \\
\hline At any time during ICU stay & $200(7.9)$ & $10(3.8)$ & 0.02 \\
\hline \multicolumn{4}{|l|}{ Corticosteroids } \\
\hline In the $1 \mathrm{st} 72 \mathrm{~h}$ of ARDS & $367(14.2)$ & $39(16.7)$ & 0.36 \\
\hline At any time during ICU stay & $467(18.1)$ & $41(17.5)$ & 0.89 \\
\hline
\end{tabular}

Categorical variables are shown as $\mathrm{n}(\%)$

ARDS, acute respiratory distress syndrome; CT, computed tomography; LHFP, left heart filling pressure; TTP, transpulmonary thermodilution device; ICU, intensive care unit; ECMO, extracorporeal membrane oxygenation

${ }^{a} p$ value represents comparisons across ARDS with or without known risk factor; parametric or nonparametric tests were used according to the distribution of variables

diagnosing unusual causes of ARDS [10] were rarely performed. Assessment of left heart filling pressure was not more common than in other patients; and (3) although these patients presented a different clinical phenotype than others, with more comorbidities and less severe pulmonary and non-pulmonary organ failures, their outcomes were not significantly different from those of patients having one or more risk factor identified.

Eight percent of patients meeting ARDS criteria within $48 \mathrm{~h}$ of acute hypoxemic respiratory failure onset had no common risk factor for ARDS identified upon ARDS diagnosis or later during the stay. This figure is consistent with a previous retrospective study, which reported a prevalence of 7.5\% [7], and confirms that this subgroup represents a significant proportion of patients with ARDS. Strikingly, an objective assessment of left heart filling pressures to rule out a pulmonary edema of the hydrostatic type was performed in less than $70 \%$ of cases, and no more frequently than in other patients, although this criterion is required by the Berlin definition of ARDS when no risk factor has been identified $[1,11]$. Thus, one cannot exclude that some of these patients had in fact a pulmonary edema of the hydrostatic type, even if managing physicians declared that the acute respiratory failure was not entirely related to cardiac failure. Of note, the comparison of patients who underwent an objective assessment 
Table 3 Risk factors and etiologies identified for ARDS patients meeting ARDS criteria within $48 \mathrm{~h}$ of acute hypoxemic respiratory failure onset $(n=2813)$

\begin{tabular}{|c|c|}
\hline \multicolumn{2}{|c|}{ Common risk factors $^{\mathrm{a}}$ identified in 2579 ARDS patients ${ }^{\mathrm{b}}$} \\
\hline Pneumonia & $1683(65.2)$ \\
\hline Non-pulmonary sepsis & $455(17.6)$ \\
\hline Aspiration of gastric contents & $402(15.6)$ \\
\hline Non-cardiogenic shock & $214(8.3)$ \\
\hline Major trauma & $112(4.3)$ \\
\hline Blood transfusion & $111(4.3)$ \\
\hline Pulmonary contusion & $87(3.4)$ \\
\hline Inhalational injury & $70(2.7)$ \\
\hline Pancreatitis & $59(2.3)$ \\
\hline Drug overdose & $51(2.0)$ \\
\hline Pulmonary vasculitis ${ }^{c}$ & $38(1.5)$ \\
\hline Burn & $8(0.3)$ \\
\hline Drowning & $2(0.1)$ \\
\hline Others $^{d}$ & $74(2.9)$ \\
\hline \multicolumn{2}{|c|}{$\begin{array}{l}\text { Etiologies for ARDS in } 234 \text { patients having no common risk } \\
\text { factor identified }\end{array}$} \\
\hline Interstitial lung disease & $9(3.8)^{\mathrm{e}}$ \\
\hline Drug-induced ARDS & $8(3.4)^{f}$ \\
\hline Massive hemoptysis & $8(3.4)$ \\
\hline Pulmonary embolism & $3(3.4)$ \\
\hline Diffuse alveolar hemorrhage & $3(3.4)$ \\
\hline Alveolar proteinosis & $3(3.4)$ \\
\hline Miscellaneous & $11(4.7)^{\mathrm{g}}$ \\
\hline No etiology identified & $189(80.8)$ \\
\hline \multicolumn{2}{|l|}{ Variables are shown as n (\%) } \\
\hline \multicolumn{2}{|c|}{ ARDS: Acute Respiratory Distress Syndrome } \\
\hline \multicolumn{2}{|c|}{ a As listed in the Berlin definition of ARDS [1] } \\
\hline \multicolumn{2}{|c|}{ b Some patients had several risk factors } \\
\hline \multicolumn{2}{|c|}{$\begin{array}{l}\text { c Including } 24 \text { patients who had both one or more common risk factors for } \\
\text { ARDS and pulmonary vasculitis }\end{array}$} \\
\hline \multicolumn{2}{|c|}{$\begin{array}{l}\mathrm{d} \text { Includes conditions likely to be associated with common risk factors (e.g., } \\
\text { major surgery }(n=23) \text {, coma/neurological disorders }(n=16) \text {, cardiogenic shock } \\
\text { or cardiac surgery with cardiopulmonary bypass }(n=9) \text {, cardiac arrest }(n=8) \text {, } \\
\text { and others }(n=18))\end{array}$} \\
\hline \multicolumn{2}{|l|}{ e With no specific diagnosis } \\
\hline \multicolumn{2}{|c|}{$\begin{array}{l}\text { f Including amiodarone }(n=4) \text {, bicalutamide }(n=1) \text {, warfarin }(n=1) \text {, } \\
\text { chemotherapy agent }(n=1) \text {, not specified }(n=1)\end{array}$} \\
\hline \multicolumn{2}{|c|}{$\begin{array}{l}\text { 9 Including lung tumoral infiltration }(n=2) \text {, acute interstitial pneumonia }(n=1) \text {, } \\
\text { Hemophagocytic Lymphohistiocytic syndrome }(n=1) \text {, lymphoproliferative } \\
\text { disease with lung involvement }(n=1) \text {, graft versus host disease }(n=1) \text {, primary } \\
\text { graft dysfunction }(n=1) \text {, gas embolism }(n=1) \text {, ovarian hyperstimulation } \\
\text { syndrome }(n=1) \text {, Castleman's disease }(n=1)\end{array}$} \\
\hline
\end{tabular}

of LHFP to those who did not (Additional file 1: e-Table 3) revealed that the latter had less cardiac and renal comorbidities, suggesting they were at lower risk of developing a mere cardiogenic pulmonary edema, possibly explaining why physicians did not deem necessary to further explore cardiac function, even if required by the Berlin definition in this setting. Eighty percent of patients within this subgroup had eventually no risk factor nor etiology retrieved,
Table 4 Lung histological analysis results obtained from open lung biopsy or autopsy in patients with and without ARDS risk factor identified

\begin{tabular}{|c|c|c|c|}
\hline Parameters & $\begin{array}{l}\text { ARDS patients } \\
\text { with } \geq 1 \text { risk factor } \\
\text { identified upon } \\
\text { ARDS diagnosis } \\
(n=2579)\end{array}$ & $\begin{array}{l}\text { ARDS patients } \\
\text { with no risk factor } \\
\text { identified upon } \\
\text { ARDS diagnosis } \\
(n=234)\end{array}$ & $p$ value \\
\hline Open lung biopsy & $5^{a}(0.2)$ & $6(2.6)$ & $<0.001$ \\
\hline DAD & 0 & $2^{b}$ & \\
\hline Pulmonary fibrosis & 0 & 2 & \\
\hline $\begin{array}{l}\text { Normal lung } \\
\text { histology }\end{array}$ & 2 & 2 & \\
\hline Autopsy & $50(5.5)$ & $6(9.4)$ & 0.26 \\
\hline Pulmonary edema & 11 & 3 & \\
\hline Pneumonia & 12 & 1 & \\
\hline DAD & 10 & 2 & \\
\hline Pulmonary fibrosis & 7 & 2 & \\
\hline Atelectasis & 4 & 1 & \\
\hline $\begin{array}{l}\text { Normal lung } \\
\text { histology }\end{array}$ & 2 & 3 & \\
\hline $\begin{array}{l}\text { Intra-alveolar } \\
\text { hemorrhage }\end{array}$ & 1 & $1^{d}$ & \\
\hline \multicolumn{4}{|c|}{ DAD, diffuse alveolar damage; AIP, acute interstitial pneumonia } \\
\hline \multicolumn{4}{|c|}{ a Results were only available for 2 patients } \\
\hline \multicolumn{4}{|c|}{$\begin{array}{l}\text { b Including one patient with spumous macrophages related to cordarone- } \\
\text { induced pneumonia }\end{array}$} \\
\hline \multicolumn{4}{|c|}{$\begin{array}{l}\text { ' Percentages have been computed with the number of decedents in the ICU as } \\
\text { the denominator. Numbers in the column do not match with the total number } \\
\text { of autopsies performed as some autopsy findings were unavailable and some } \\
\text { patients had several histological findings }\end{array}$} \\
\hline${ }^{d}$ Due to massive her & tysis & & \\
\hline
\end{tabular}

demonstrating that in spite of an extensive literature on the unusual etiologies of ARDS (e.g., auto-immune and drug-induced diseases, organizing pneumonia, diffuse alveolar hemorrhage, lung tumor infiltration, acute pulmonary edema, pulmonary embolism) $[7,12-14]$ mainly coming from autopsy $[4,15]$ or lung biopsy studies [1618 ], under "real-life" conditions, no etiological diagnosis is made in most of the cases. Indeed, in the current series, although chest CT scans were more frequently performed in patients with no risk factor than in others, key investigations aimed at identifying the cause of ARDS, including BAL cytological examination, immunological tests [10] and open lung biopsy [19] were performed in a minority of cases $(9,5$, and $3 \%$, respectively), despite the fact that investigators were prospectively requested to fill in a dedicated form addressing these aspects. This failure to identify the cause of ARDS in $80 \%$ of patients from the no risk factor group suggests that the individualization of patients' management might have not been optimal. Indeed, specific interventions have been suggested to be beneficial in targeted cases. For instance, patients with auto-immune or 


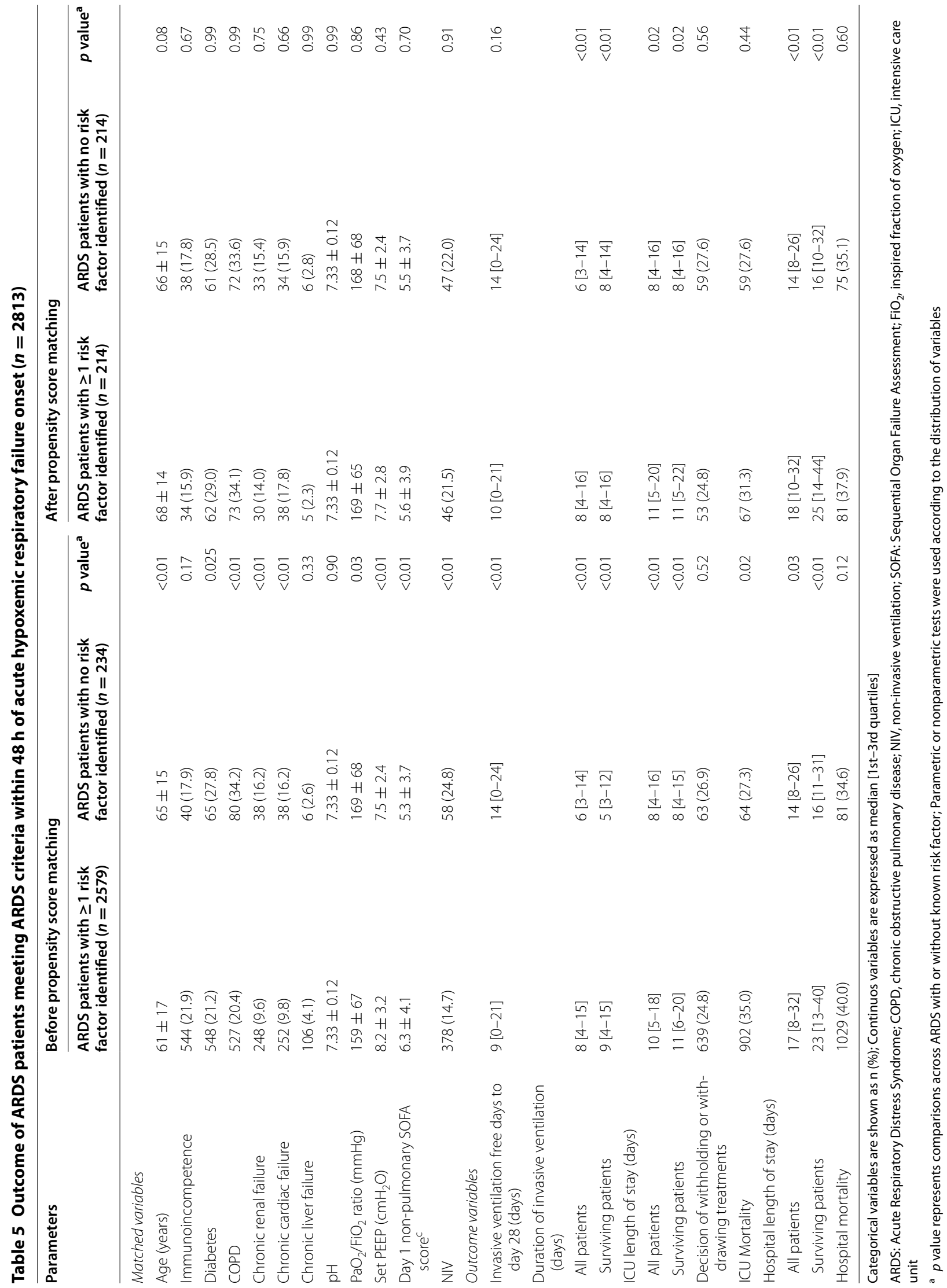


drug-induced disorders, organizing pneumonia, or diffuse alveolar hemorrhage could benefit from anti-inflammatory treatments (e.g., corticosteroids) [7, 12, 13]. Interestingly, patients from the no risk factor group did not receive more frequent corticosteroids than others, both within $72 \mathrm{~h}$ of ARDS onset and during ICU stay, and the overall rate of corticosteroids administration was low (about 18\%). In all, our findings suggest that the low diagnostic yield in the subgroup of ARDS patients with no risk factor precluded the administration of individualized treatments. Other differences observed in treatments administered (i.e., neuromuscular blocking agents and inhaled vasodilators) and mechanical ventilation settings between both groups of patients likely resulted from differences in patients' severity.

The current study provides a picture of the clinical presentation of ARDS patients with no risk factor

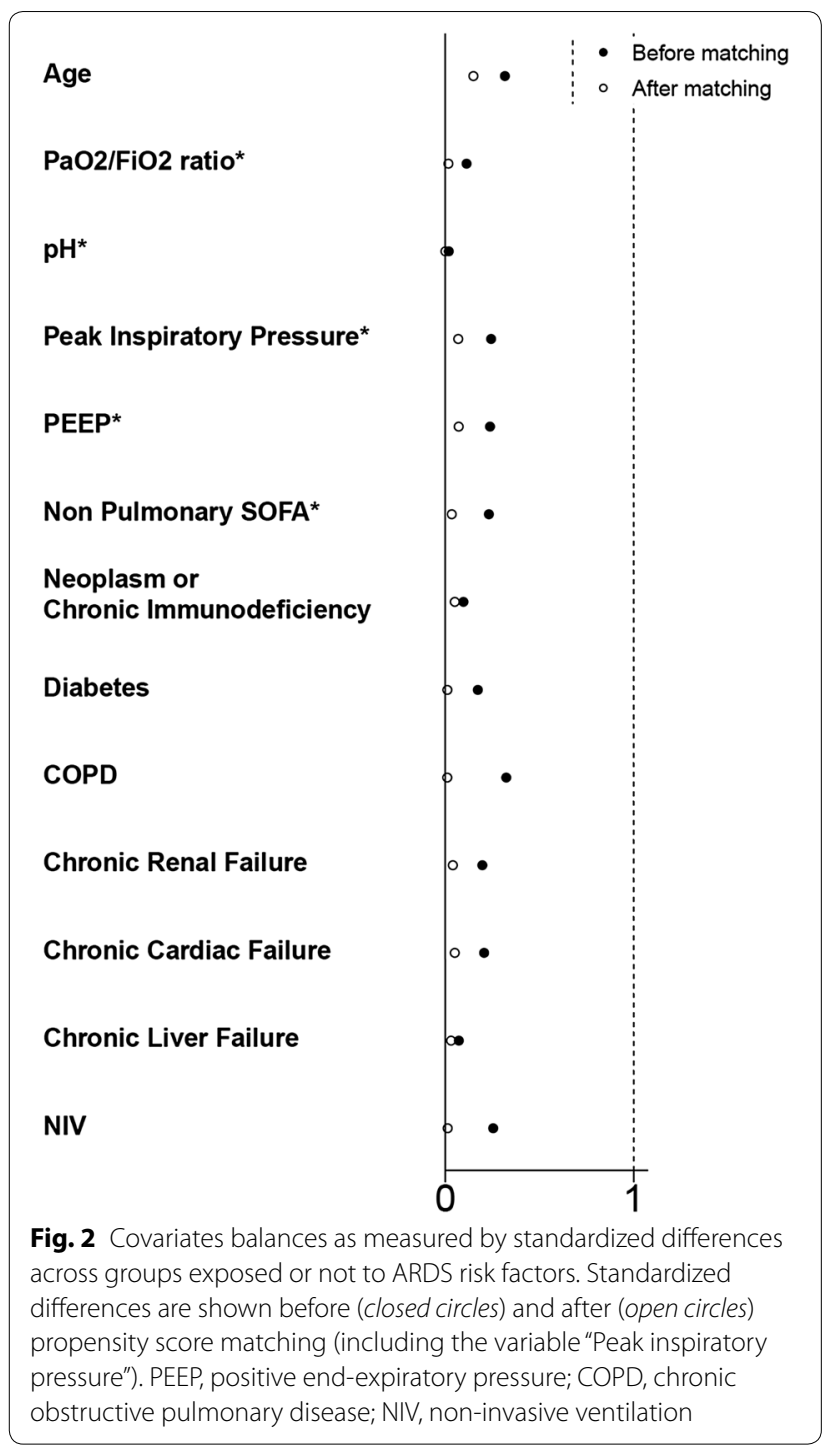

identified and shows that these patients have a different clinical phenotype than others. Indeed, we not only observed differences regarding patients age and comorbidities, but also regarding the severity of ARDS and of associated organ failures, patients with no risk factor being less severe than others. Of note, such phenotype differences between patients without and with ARDS risk factors match those observed between patients with non-DAD vs. DAD ARDS, as recently shown in lung biopsy series [3, 16-18]. This observation corroborates the hypothesis that ARDS with no risk factor might be associated with a greater proportion of non-DAD lung histologies (sometimes termed "ARDS mimickers" [7, $13,20])$ than ARDS with one or more identified risk factors. However, we could not confirm this hypothesis due to the limited number of histological examinations performed in our study. In fact, the rate of open lung biopsy performed was strikingly low $(n=11 / 2813$ in total, $0.4 \%$ of the whole cohort), illustrating that this procedure is exceptionally performed in ARDS patients. Yet, previous studies suggested that open lung biopsy, when performed in carefully selected patients, might not only allow for distinguishing patients with DAD and non-DAD ARDS, as discussed above, but have also been reported to allow for diagnoses to be made in $84 \%$ of cases and to alter management in $73 \%$ [21]. Thus, we believe that in patients with persisting ARDS, when a comprehensive diagnostic work-up has been performed, including-but not limited to-bronchoscopy with BAL fluid examination with extended microbiological and cytological analyses, CT scan examination, and immunological tests, and when no definite diagnosis has been retained, there might be room for open lung biopsy [12]. Of note, studies aiming at assessing the performances of a diagnostic work-up/algorithm in ARDS patients have, to the best of our knowledge, never been performed and would certainly be welcome.

In the current study, patients with no ARDS risk factor identified had a lower ICU mortality but no statistically different hospital mortality, as compared with others. A propensity score-matched analysis further confirmed the lack of significant differences both in ICU and hospital mortality between patients with and without ARDS risk factors, suggesting that the ICU mortality difference observed in the whole cohort was likely related to associated factors rather than to the lack of ARDS risk factor identification per se. Such results contrast with a previous study [7], in which we had reported a significant relationship between the lack of ARDS risk factor and mortality. Several factors might account for these conflicting results including differences in case mix and in patients' management, particularly regarding the diagnostic work-up performed and the administration of 

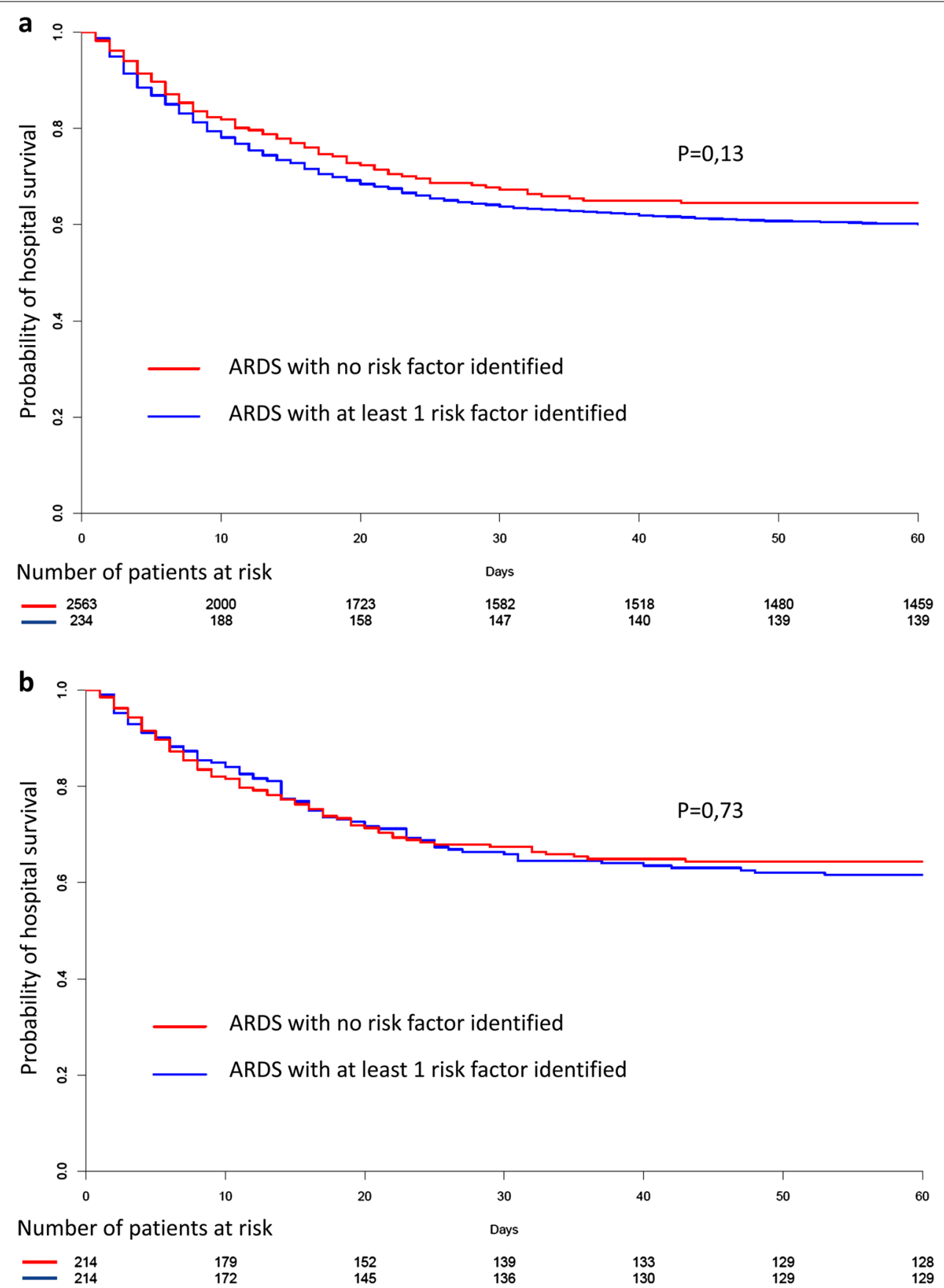

Fig. 3 Kaplan-Meier curves of hospital survival probability in the whole (non-matched) cohort (a) and in the propensity score-matched cohort (b). ARDS patients with no risk factor identified (red curve) exhibited a non-significantly different probability of mortality during hospital stay, as compared with those having one or more risk factor identified (blue curve) both in the whole ( $\mathbf{a}, p=0.13$, by the log-rank test) and the matched cohort (b, $p=0.73$ by the Cox proportional hazard model)

corticosteroids in patients having no risk factor identified. We can only speculate on whether a more extensive work-up could have provided more diagnosis responding to specific therapies [10, 22, 23]. Indeed, the lack of specific procedures in most patients of the no risk factor group (e.g., BAL, lung biopsy) suggests that other diagnoses may have been missed. A special effort should be made in the future to target this group through guidelines and recommendations.

Our study has the following limitations: First, the current study is an ancillary study of a large prospective, international, multicenter study [8], and was thus not 
Table 6 Univariable logistic regression analysis assessing the relationship between the absence of identified ARDS risk factor and mortality before and after propensity score matching

\begin{tabular}{llll}
\hline & OR & 95\% IC & $\boldsymbol{p}$ value \\
\hline ICU mortality before matching & 0.70 & $0.52-0.94$ & 0.02 \\
ICU mortality after matching & 0.84 & $0.55-1.27$ & 0.40 \\
Hospital mortality before matching & 0.79 & $0.60-1.05$ & 0.11 \\
Hospital mortality after matching & 0.89 & $0.60-1.31$ & 0.55 \\
\hline
\end{tabular}

$\mathrm{ICU}$, intensive care unit

specifically designed for studying the subgroup of ARDS patients with no risk factor. However, the current study had been designed and approved before the enrollment period began and a dedicated section of the online case report form had been elaborated a priori for the prospective collection of data pertaining to ARDS with no risk factor; Second, although this study was performed in 459 ICUs worldwide, selection bias related to participating centers might have occurred, thereby limiting the generalizability of the findings; Third, we lacked access to the source data, implying that patients with ARDS might have been missed and that risk factors for ARDS might have been omitted, and thus some patients misclassified.

\section{Conclusion}

About eight percent of patients with ARDS have no risk factor identified and exhibit a different clinical phenotype, with more pre-existing chronic illnesses and less severe pulmonary and non-pulmonary organ failures than others. Thirty percent of these patients lacked an objective assessment of left heart filling pressure while $80 \%$ of them had no accurate etiological diagnosis made with most of them undergoing a limited diagnostic workup, likely limiting the individualization of patient management. Compared to patients with ARDS of similar severity but with identified risk factors, their outcome was similar. Prospective studies should propose a specific work-up and test whether this can improve outcomes.

\section{Additional file}

Additional file 1. Online supplement (Methods and Results), list of LUNG SAFE investigators (e-Appendix 1) and supplemental form to be filled for patients with no ARDS risk factor identified (e-Appendix 2).

\section{Abbreviations}

ARDS: acute respiratory distress syndrome; BAL: broncho-alveolar lavage; ICU: intensive care unit; PEEP: positive end-expiratory pressure.

Authors' contributions

NDP, TP, LB, AM, JL, EF and BM designed the study; TP performed the statistical analyses; NDP and TP wrote the initial draft of the manuscript; All authors revised the manuscript for important intellectual content. All authors read and approved the final manuscript.

\section{Author details}

${ }^{1}$ Service de Réanimation Médicale, DHU A-TVB, Hôpitaux Universitaires Henri Mondor, Assistance Publique-Hôpitaux de Paris, Créteil Cedex 94010, France. ${ }^{2}$ Groupe de Recherche Clinique CARMAS, Faculté de Médecine de Créteil, Université Paris Est Créteil, Créteil Cedex 94010, France. ${ }^{3}$ Groupe hospitalier des Hôpitaux Universitaires de l'Est Parisien, Pôle Thorax Voies aériennes, Unité de Réanimation médico-chirurgicale, Hôpital Tenon, AP-HP, Paris, France. ${ }^{4}$ ECSTRA Team, Inserm, UMR 1153, Univ Paris Diderot, Sorbonne Paris Cité, Paris, France. ${ }^{5}$ Inserm, UMR 915, Université Paris Est Créteil, Créteil Cedex, France. ${ }^{6}$ Keenan Research Centre, Li Ka Shing Knowledge Institute, St Michael's Hospital, Toronto, Canada. ${ }^{7}$ Interdepartmental Division of Critical Care Medicine, University of Toronto, Toronto, Canada. ${ }^{8}$ School of Medicine and Surgery, University of Milan-Bicocca, Monza, Italy. ${ }^{9}$ Department of Emergency and Intensive Care, San Gerardo Hospital, Monza, Italy. ${ }^{10}$ Departments of Anesthesia and Critical Care Medicine, Keenan Research Centre for Biomedical Science, St Michael's Hospital, Toronto, Canada. ${ }^{11}$ Departments of Anesthesia, Physiology and Interdepartmental Division of Critical Care Medicine, University of Toronto, Toronto, Canada. ${ }^{12}$ Service de Réanimation Médicale, Centre Hospitalier Universitaire d'Angers, Angers, France. ${ }^{13}$ Service de Réanimation Médicale, Hôpital Henri Mondor, 51, Avenue du Maréchal de Lattre de Tassigny, 94010 Créteil Cedex, France.

\section{Acknowledgements}

The authors thank the LUNG SAFE investigators (see Additional file 1: e-Appendix 1) for including patients in the study and collecting data.

LUNG SAFE investigators and the ESICM trials group are listed in the Additional file 1: e-Appendix 1.

\section{Competing interests}

$\mathrm{NDP}, T P, G C, A M D, C B B, E F, G C, J L, A M$, and BM declare that they have no conflict of interest; $L B$ declares having received research grants from Fisher Paykel and Covidien, personal fees from Air Liquide, and non-financial support from Fisher Paykel, Maquet, Air Liquide and Philips.

\section{Availability of data and materials}

The dataset supporting the conclusions of this article is available on request from nicolas.de-prost@aphp.fr.

\section{Ethics approval and consent to participate}

Ethics committee approval was obtained by all participating ICUs and patient consent or ethics committee waiver of consent were required.

Funding

European Society of Intensive Care Medicine (ESICM).

\section{Publisher's Note}

Springer Nature remains neutral with regard to jurisdictional claims in published maps and institutional affiliations.

Received: 25 February 2017 Accepted: 23 May 2017

Published online: 19 June 2017

References

1. Force Ards Definition Task, Ranieri VM, Rubenfeld GD, Thompson BT, Ferguson ND, Caldwell E, et al. Acute respiratory distress syndrome: the Berlin Definition. JAMA. 2012;307:2526-33.

2. Gajic O, Dabbagh O, Park PK, Adesanya A, Chang SY, Hou P, et al. Early identification of patients at risk of acute lung injury: evaluation of lung injury prediction score in a multicenter cohort study. Am J Respir Crit Care Med. 2011;183:462-70.

3. Kao KC, Hu HC, Chang CH, Hung CY, Chiu LC, Li SH, et al. Diffuse alveolar damage associated mortality in selected acute respiratory distress syndrome patients with open lung biopsy. Crit Care. 2015;19:228. 
4. Thille AW, Esteban A, Fernandez-Segoviano P, Rodriguez JM, Aramburu JA, Penuelas $\mathrm{O}$, et al. Comparison of the Berlin definition for acute respiratory distress syndrome with autopsy. Am J Respir Crit Care Med. 2013;187:761-7.

5. Gattinoni L, Pelosi P, Suter PM, Pedoto A, Vercesi P, Lissoni A. Acute respiratory distress syndrome caused by pulmonary and extrapulmonary disease. Different syndromes? Am J Respir Crit Care Med. 1998;158:3-11.

6. Calfee CS, Delucchi K, Parsons PE, Thompson BT, Ware LB, Matthay MA, et al. Subphenotypes in acute respiratory distress syndrome: latent class analysis of data from two randomised controlled trials. The Lancet Respiratory medicine. 2014;2:611-20.

7. Gibelin A, Parrot A, Maitre B, Brun-Buisson C, Mekontso Dessap A, Fartoukh $M$, et al. Acute respiratory distress syndrome mimickers lacking common risk factors of the Berlin definition. Intensive Care Med. 2016:42:164-72.

8. Bellani G, Laffey JG, Pham T, Fan E, Brochard L, Esteban A, et al. Epidemiology, patterns of care, and mortality for patients with acute respiratory distress syndrome in intensive care units in 50 countries. JAMA 2016;315:788-800.

9. Haukoos JS, Lewis RJ. The propensity score. JAMA. 2015;314:1637-8.

10. Papazian L, Calfee CS, Chiumello D, Luyt CE, Meyer NJ, Sekiguchi $\mathrm{H}$, et al. Diagnostic workup for ARDS patients. Intensive Care Med. 2016;42:674-85

11. Ferguson ND, Fan E, Camporota L, Antonelli M, Anzueto A, Beale R, et al. The Berlin definition of ARDS: an expanded rationale, justification, and supplementary material. Intensive Care Med. 2012;38:1573-82.

12. Guerin C, Thompson T, Brower R. The ten diseases that look like ARDS. Intensive Care Med. 2015;41:1099-102.

13. Schwarz MI, Albert RK. "Imitators" of the ARDS: implications for diagnosis and treatment. Chest. 2004;125:1530-5.

14. Patel SR, Karmpaliotis D, Ayas NT, Mark EJ, Wain J, Thompson BT, et al. The role of open-lung biopsy in ARDS. Chest. 2004;125:197-202.
15. Esteban A, Fernandez-Segoviano P, Frutos-Vivar F, Aramburu JA, Najera $L$, Ferguson ND, et al. Comparison of clinical criteria for the acute respiratory distress syndrome with autopsy findings. Ann Intern Med. 2004;141:440-5.

16. Cardinal-Fernandez P, Bajwa EK, Dominguez-Calvo A, Menendez JM, Papazian $L$, Thompson BT. The presence of diffuse alveolar damage on open lung biopsy is associated with mortality in patients with acute respiratory distress syndrome: a systematic review and meta-analysis. Chest. 2016;149:1155-64.

17. Guerin C, Bayle F, Leray V, Debord S, Stoian A, Yonis H, et al. Open lung biopsy in nonresolving ARDS frequently identifies diffuse alveolar damage regardless of the severity stage and may have implications for patient management. Intensive Care Med. 2015:41:222-30.

18. Lorente JA, Cardinal-Fernandez P, Munoz D, Frutos-Vivar F, Thille AW Jaramillo C, et al. Acute respiratory distress syndrome in patients with and without diffuse alveolar damage: an autopsy study. Intensive Care Med. 2015;41:1921-30

19. Papazian L, Doddoli C, Chetaille B, Gernez Y, Thirion X, Roch A, et al. A contributive result of open-lung biopsy improves survival in acute respiratory distress syndrome patients. Crit Care Med. 2007;35:755-62.

20. Aublanc $M$, Perinel S, Guerin C. Acute respiratory distress syndrome mimics: the role of lung biopsy. Curr Opin Crit Care. 2017:23:24-9.

21. Libby LJ, Gelbman BD, Altorki NK, Christos PJ, Libby DM. Surgical lung biopsy in adult respiratory distress syndrome: a meta-analysis. Ann Thorac Surg. 2014;98:1254-60.

22. Brochard $L$, Pham T, Rubenfeld $G$. Does my patient really have ARDS? Intensive Care Med. 2016:42:656-8.

23. Cardinal-Fernandez P, Pey C, Kao KC. ARDS: Time to "separate the wheat from the chaff". J Crit Care. 2016:34:31-2.

\section{Submit your manuscript to a SpringerOpen ${ }^{\circ}$ journal and benefit from:}

- Convenient online submission

- Rigorous peer review

- Open access: articles freely available online

- High visibility within the field

- Retaining the copyright to your article

Submit your next manuscript at $\boldsymbol{\nabla}$ springeropen.com 